\title{
Theory of global cooling
}

\author{
Md. Faruque Hossain ${ }^{1,2}$
}

\begin{abstract}
Background: Due to the consequence of industrial $\mathrm{CO}_{2}$ emission, the surface temperature of Earth is rising at an alarming rate, causing accelerating deadly effects on the environment and living beings. Thus, an approach to mitigate global warming has been proposed by breaking down industrial $\mathrm{CO}_{2}$ and converting it into useful products. Methods: Lithium nitride $\left(\mathrm{Li}_{3} \mathrm{~N}\right)$, the only stable alkali metal nitride that reacts readily with $\mathrm{CO}_{2}$, has been proposed to use as a means to break down $\mathrm{CO}_{2}$. For this, a chemical reactor has been proposed to install at industrial $\mathrm{CO}_{2}$-releasing tower to capture $\mathrm{CO}_{2}$ and allow a heat-releasing reaction into the bioreactor in the presence of $\mathrm{Li}_{3} \mathrm{~N}$ to convert it into carbon $(\mathrm{C})$, nitrogen $\left(\mathrm{N}_{2}\right)$, oxygen $\left(\mathrm{O}_{2}\right)$, and lithium cyanamide $\left(\mathrm{Li}_{2} \mathrm{CN}_{2}\right)$. In order to confirm this theoretical viability of this technology, a series of global environmental issues has also been discussed to neutralize global warming by utilizing this simple technology.

Results: The by-products lithium cyanamide $\left(\mathrm{Li}_{2} \mathrm{CN}_{2}\right)$ is environmentally benign and can be used as fertilizer, and subsequently, the additional products $\left(\mathrm{C}_{1} \mathrm{~N}_{2}\right.$ and $\left.\mathrm{O}_{2}\right)$ from this reaction naturally will mitigate the atmospheric and biospheric chemical cycle.

Conclusions: The technology indeed would be an innovative field of carbon management science which will not only break down the deadly $\mathrm{CO}_{2}$ but also produce useful products like $\mathrm{Li}_{2} \mathrm{CN}_{2}$ (a fertilizer) and $\mathrm{C}_{1} \mathrm{~N}_{2}$, and $\mathrm{O}_{2}$ to balance the atmosphere and biosphere; thus, global warming comes to an end in the near future.
\end{abstract}

Keywords: Climate change, Carbon capture, Lithium nitride $\left(\mathrm{Li}_{3} \mathrm{~N}\right)$, Carbon dioxide breakdown, Environmental impact

\section{Background}

In the mid-1990s, an understanding of the many processes that lead to emissions of heat-trapping greenhouse gasses, in particular $\mathrm{CO}_{2}$, had been reached. Just before the Industrial Revolution, the concentration of $\mathrm{CO}_{2}$ in the atmosphere was about $280 \mathrm{ppm}$, which nearly doubled to $560 \mathrm{ppm}$ in 2015 [2, 9]. Earth has its own natural greenhouse effect whereby greenhouse gasses in the atmosphere allow sunlight to enter but absorb heat radiation. Because these gasses absorb the heat, an average surface temperature of around $15{ }^{\circ} \mathrm{C}$ is maintained. Without it, the average surface temperature would be around $0{ }^{\circ} \mathrm{F}$. Due to the burning of fossil fuels and other human activities, the concentration of greenhouse gasses in our atmosphere has increased and this has resulted in more heat being retained in the atmosphere and an increase in global average surface temperatures. In 2015, $9.8 \mathrm{Gt}$ of $\mathrm{C}$ or $35.9 \mathrm{Gt}$ of $\mathrm{CO}_{2}$ were

\footnotetext{
Correspondence: faruque55@aol.com

${ }^{1}$ Department of Civil and Urban Engineering, New York University, 6

Metrotech Center, Brooklyn, NY 11201, USA

${ }^{2}$ Green Globe Technology, 4323 Colden Street 15L, Flushing, NY 11355, USA
}

emitted from fossil fuel use worldwide [6]. This accounted for about $91 \%$ of the total global $\mathrm{CO}_{2}$ emissions and originated from coal (42\%), oil (33\%), gas (19\%), cement (6\%), and gas flaring (1\%) (Fig. 1).

In addition, land use change (for example, the clearing of forests to make room for grazing or farm land) alters the amount of sunlight reflected from the ground back into space (the surface albedo) [15]. The scale of these changes is estimated to be about one fifth of the forcing on the global climate due to changes in emissions of greenhouse gasses. The largest impact of deforestation is estimated to be at high latitudes, where the albedo of snow-covered land that was previously forested has increased; snow on trees reflects only about half of the sunlight falling on it, whereas snow-covered open ground reflects about two thirds. Other significant changes in the land surface resulting from human activities include tropical deforestation, which changes evapotranspiration rates (the amount of water vapor released into the atmosphere by evaporation and transpiration from trees), desertification, which increases surface albedo, and the general effects of agriculture on soil 


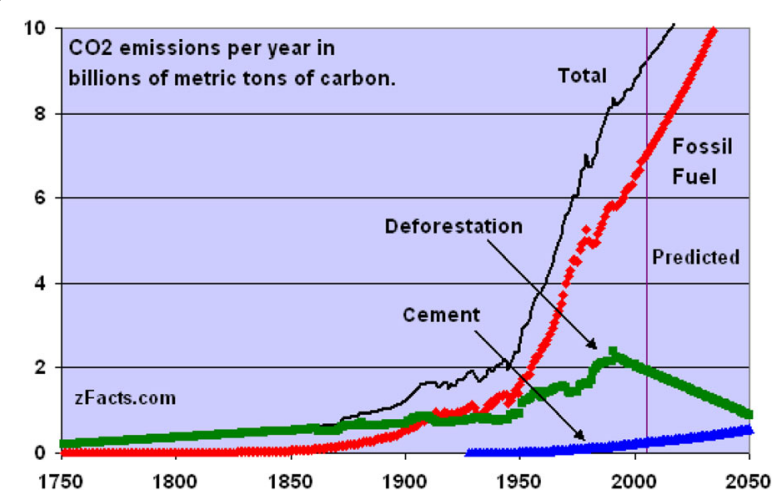

Fig. 1 Fossil fuel data from the US Department of Energy, including an estimate that fossil fuel-based emissions will increase at $1.2 \%$ per year until 2030

moisture characteristics. To neutralize this deadly effect, an innovative step has been proposed; sophisticated chemical reactions are used to break down greenhouse gasses, and a series of mathematical calculations are performed to achieve a theoretical solution to global climate change. The proposed method will provide us with useful information and, perhaps, lead to a practical implementation of the proposed theory.

\section{Methods}

Because $\mathrm{CO}_{2}$ molecules are very stable, a device will be used that can sink industrial $\mathrm{CO}_{2}$ to produce useful products through a heat-release reaction between $\mathrm{CO}_{2}$ and lithium nitride $\left(\mathrm{Li}_{3} \mathrm{~N}\right)$. This is to be done by reacting lithium with nitrogen at room temperature. Reacting lithium nitride with carbon dioxide will react to give results in amorphous carbon nitride $\left(\mathrm{C}_{3} \mathrm{~N}_{4}=\mathrm{C}+\mathrm{N}_{2}\right)$, a semiconductor, and lithium cyanamide $\left(\mathrm{Li}_{2} \mathrm{CN}_{2}\right)$, a precursor to fertilizers. Besides fertilizer production, the other advantageous products of this reaction will be $\mathrm{O}_{2}$ and $\mathrm{N}_{2}$, which shall equilibrate the atmospheric chemical cycle via a low-energy impact chemical reaction. The reaction of $\mathrm{Li}_{3} \mathrm{~N}$ with $\mathrm{CO}_{2}$ at room temperature is exothermic and proceeds as follows:

$$
\mathrm{CO}_{2}+\mathrm{Li}_{3} \mathrm{~N} \rightarrow \mathrm{C}_{3} \mathrm{~N}_{4}+\mathrm{O}_{2}+\mathrm{Li}_{2} \mathrm{CN}_{2}
$$

$\mathrm{C}_{3} \mathrm{~N}_{4}=\mathrm{C}+\mathrm{N}_{2}$.

$\mathrm{C}_{3} \mathrm{~N}_{4}$ is an amorphous carbon nitride-a semiconductor-and lithium cyanamide $\left(\mathrm{Li}_{2} \mathrm{CN}_{2}\right)$ is a precursor to fertilizers. The other products of this reaction are $\mathrm{O}_{2}$ and $\mathrm{N}_{2}$, which will equilibrate the atmospheric chemical cycle by implementing a low-energy-impact chemical reaction as above.

Once the $\mathrm{CO}_{2}$ is managed as per the technology described above, it is predicted that the atmosphere will be sufficiently clean to equilibrate its chemical composition. We define the temperature of a "clean atmosphere" in which excess carbon dioxide is captured using the equation $\hat{T}=T_{\mathrm{e}}$, where $\hat{T}$ is the planet's equilibrium surface temperature and $T_{\mathrm{e}}$ is the planet's effective temperature. If we assume that the planet rotates with period $P$, in order for energy to travel from one hemisphere (for instance, as experienced in a day) to the other, it must be conducted through the materials that make up the surface. This process is sufficiently slow that each hemisphere can be thought of as being isolated from the other. Day and night are assumed to have equal durations, of $P / 2$. Furthermore, it was assumed that Flux out $=\sigma T^{4}$, but Flux in $=a \Omega / 4$. Therefore, $T_{\mathrm{e}}=a \Omega / 4=\sigma T^{4}$ and thus $T_{\mathrm{e}}$ $=(a \Omega / 4 \sigma)^{1 / 4}$, which is nearly $261 \mathrm{~W} / \mathrm{m}^{2}$. The effective temperature is the temperature that controls the diurnal surface temperature of the Earth, which has been established based on a prediction of global annual temperature-derived from verifiable analysis of spatiotemporal climate change patterns for the last 500 years-and an empirical approach that estimates the relationship between global temperature changes [9]. The solar constant, denoted as Flux in $=a \Omega / 4$, represents the total power that reaches the planet for every square meter of the Earth's surface area, which is $\Omega=1052 \mathrm{~W} / \mathrm{m}^{2}$ [11].

From the perspective of the Sun, the Earth is a circle, not a sphere, so incoming solar radiation is received by a circle with area $r^{2}$, where $r$ is the radius of the Earth. If we average the amount of solar energy received by that disk $\left(\pi r^{2} \Omega\right)$ over the entire surface of the Earth $\left(4 \pi r^{2}\right)$, the average solar energy received by the Earth per unit area of the surface of the Earth is $\pi r^{2} \Omega / 4 \pi r^{2}=\Omega / 4$, and flux in is equal to $a \Omega / 4$. Because there is a flux in, there must be a flux out. For flux out, the assumption was made that the Earth behaves like a blackbody; the Stefan-Boltzmann law can be used to write an expression for Flux out $=\sigma T^{4}$, where $\sigma$ is the Stefan-Boltzmann constant $(\sigma=$ $5.67 \times 10^{-8} \mathrm{~W} / \mathrm{m}^{2} \mathrm{~K}^{4}$ ) and $T$ is the temperature of the blackbody. The effective temperature of the Earth, $T_{e}$, is the temperature that can be explained by Flux in $=$ Flux out, where Flux in $=a \Omega / 4$ and Flux out $=\sigma T^{4}$. Therefore, the effective temperature would be $a \Omega / 4$ $=\sigma T^{4}$; thus, $T_{\mathrm{e}}=(a \Omega / 4 \sigma)^{1 / 4}$, equivalent to $261 \mathrm{~W} / \mathrm{m}^{2}$, which causes global warming (Fig. 2).

It is necessary to neutralize the $261 \mathrm{~W} / \mathrm{m}^{2}$ effective temperature to cool the Earth. To neutralize this effective temperature, the new equilibrium must be computed based on a $91 \% \mathrm{CO}_{2}$ reduction, which can be done once the above described technology is applied to all $\mathrm{CO}_{2}$ emission industries. Thus, only $9 \%$ of $\mathrm{CO}_{2}$ emissions remain, yielding an effective surface temperature of $23.5 \mathrm{~W} / \mathrm{m}^{2}$, which represents a reduction in surface temperature of $0.74 \mathrm{C} / \mathrm{m}^{2}$. Once $\mathrm{CO}_{2}$ is captured and 


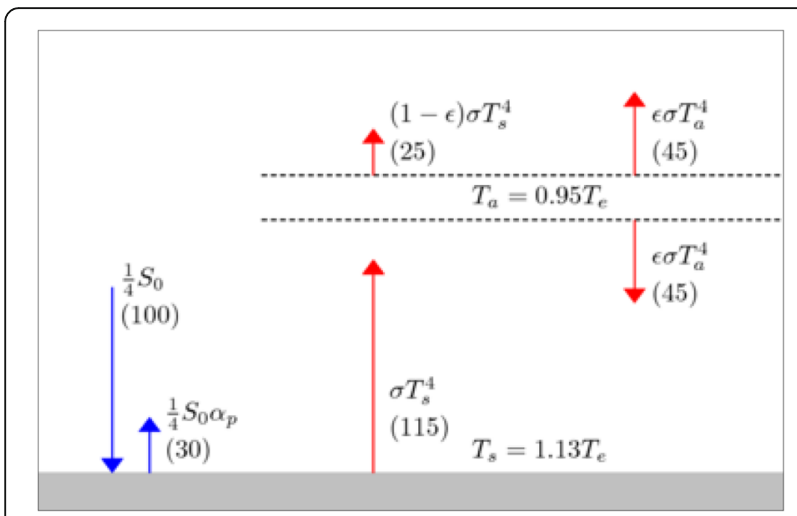

Fig. 2 The idealized flux in and flux out impact on diurnal temperature shows the relationship of the impact of radiation with respect to effective temperature. Blue arrows denote shortwave (solar) radiative flux density; red arrows denote longwave (terrestrial) radiative flux out and disperse density

transformed into useful products, the proposed reaction shall play a dramatic role in keeping the planet cool.

\section{Results and discussion}

Global warming impacts the health of humans, economies, and ecosystems around the world [1]. It is impossible to advance the definition of the dangers of global warming without developing a sustainable mechanism to solve the problem scientifically $[4,5]$. In general, it is the effective temperature (difference between flux in and out) that is caused by $\mathrm{CO}_{2}$ gasses in the atmosphere (Fig. 3).

Emissivity $(\epsilon)$ is related to the concentration of $\mathrm{CO}_{2}$ in the atmosphere; if atmospheric $\mathrm{CO}_{2}$ concentration increases, $\epsilon$ increases because of the increase in the longwave radiation absorbance and emitting capacity of the atmosphere. The result is surface warming.

Due to climate change, the projections paint a portrait of increasing ecological change and stress in Earth's biosphere, with many plant and animal species facing

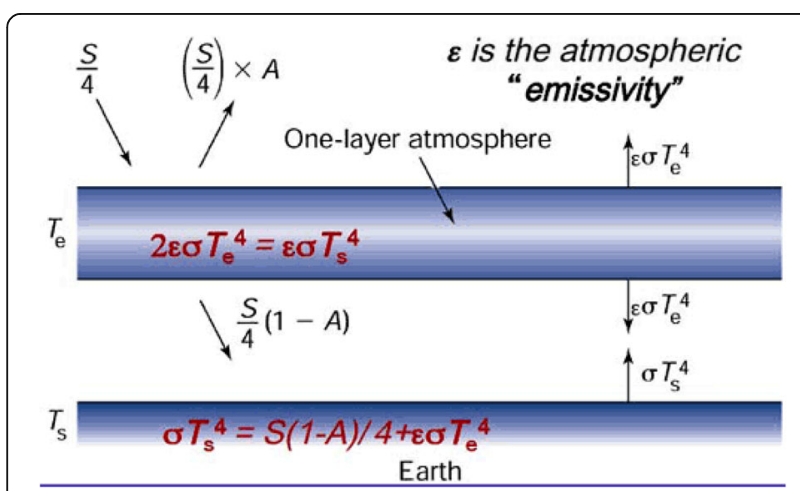

Fig. 3 Temperature balance of the Earth with the output and input from space, the atmosphere and the planet's surface represented by transparent to solar radiation and infrared emissivity $\varepsilon$ increasing competition for survival, as well as significant species turnover into functional gene derivative thus species invade areas occupied by other species [7] (Fig. 4).

In addition to altering plant communities, it has been described that climate change also disrupts the ecological balance between interdependent and often endangered plant and animal species, reduces biodiversity, and adversely affects Earth's water, energy, carbon, and other element cycles [6, 7]. For more than 25 years, scientists have warned of the possibility of climate change causing melting glaciers, rising sea levels, and other environmental changes and ecological consequences. Thus, the results of stabilizing $\mathrm{CO}_{2}$ concentrations would indeed prevent severe damage to at least one unique ecosystem, the atmospheric chemical cycle, and as a consequence have an effect on global warming $[12,13]$.

It was estimated that by 2100 , global climate change will modify plant communities covering almost half of Earth's land surface and will drive the conversion of nearly $40 \%$ of land-based ecosystems from one major ecological community type such as forest, grassland, or tundra toward another, according to a new NASA and university computer modeling study $[2,16]$. Researchers from NASA's Jet Propulsion Laboratory and the California Institute of Technology in Pasadena, CA, investigated how Earth's plant life is likely to react over the next three centuries as Earth's climate changes in response to rising levels of human-produced greenhouse gasses [7, 9] (Fig. 5).

The projections paint a portrait of increasing ecological change and stress in Earth's biosphere, with many plant and animal species facing increasing competition for survival, as well as significant species turnover, as some species invade areas occupied by other species $[4,8]$. Most of Earth's land that is not covered by ice or desert is projected to undergo at least a $30 \%$ change in plant cover changes that will require humans and animals to adapt and often relocate.

When faced with climate change, plant species often must "migrate" over multiple generations, as they can only survive, compete, and reproduce within the range of climates to which they evolutionarily and physiologically adapted. While Earth's plants and animals have evolved to migrate in response to seasonal environmental changes and to even larger transitions, such as the end of the last ice age, they often are not equipped to keep up with the rapidity of modern climate changes that are currently taking place. Human activities, such as agriculture and urbanization, are increasingly destroying Earth's natural habitats and frequently block plants and animals from successfully migrating.

In addition, researchers found a biome, or major ecological community type has been shifted, toward Earth's poles most dramatically in temperate grasslands and boreal forests and toward higher elevations due to 


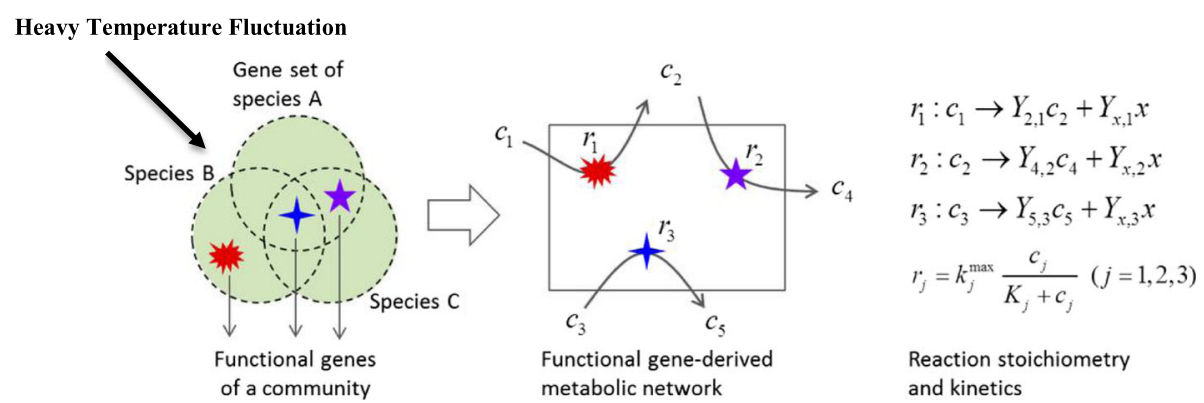

Fig. 4 The figure shows the mathematical impact of global warming changing the functional gene-derived metabolic work of the vegetation and forcing the species becoming survival for the fittest while vegetation community losing its diversity

climate change [10, 14]. Ecologically sensitive "hotspots" areas projected to undergo the greatest degree of species turnover that were identified by the study include regions in the Himalayas and the Tibetan Plateau, eastern equatorial Africa, Madagascar, the Mediterranean region, southern South America, and North America's Great Lakes and Great Plains areas [11, 12]. The largest areas of ecological sensitivity and biome changes predicted for this century are, not surprisingly, found in areas with the most dramatic climate change: in the Northern Hemisphere high latitudes, particularly along the northern and southern boundaries of boreal forests.

Thus, breaking down $\mathrm{CO}_{2}$ concentrations and stabilizing it at a comfort level would only prevent severe damage

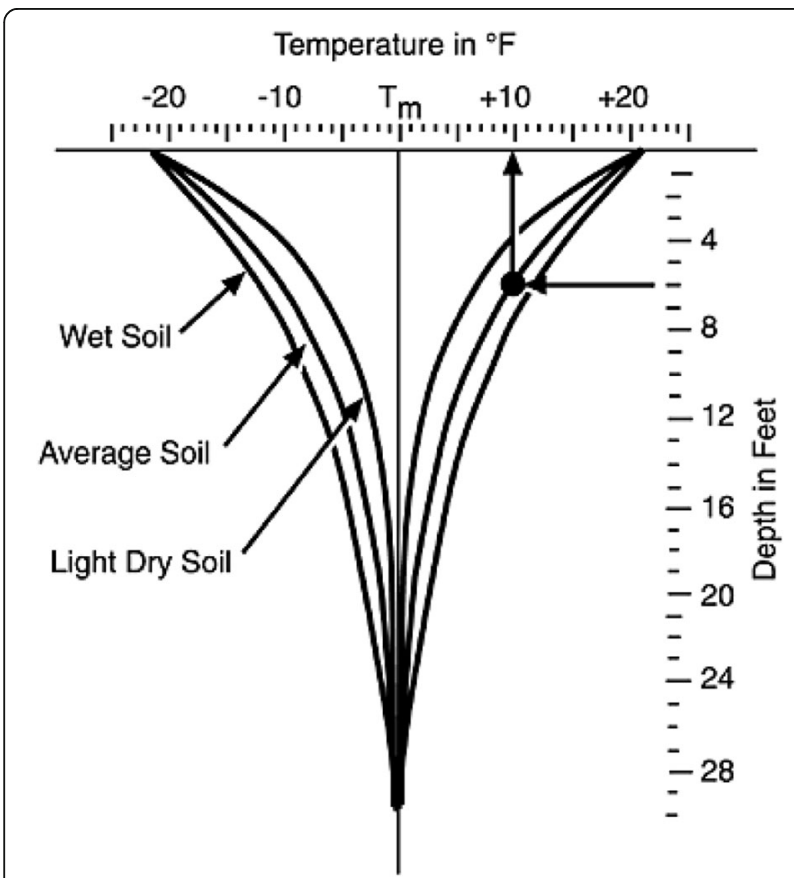

Fig. 5 Effect of temperature variation of the Earth's subsurface for depths between 0 and $30 \mathrm{ft}$; wet soil, average soil, and light dry soil are severely affected by absorbed temperature at depths of up to $6 \mathrm{ft}$ to at least one unique ecosystem, the atmospheric chemical cycle, and as a consequence have an effect on global warming.

\section{Conclusions}

It is well established that greenhouse gasses, primarily $\mathrm{CO}_{2}$ from the burning of fossil fuels, are through their heat-trapping capacity having a dangerous warming effect on Earth's temperature. In addition, human activities are changing the face of the planet through agriculture, land use change, and urbanization and affecting atmospheric chemistry and biosphere balance. Rising sea levels, changes precipitation, and in some areas, increases in frequency and intensity of extreme weather events threaten the long-term ability of human beings to live life as we currently know it $[3,7]$. Adapting to and mitigating the effects of climate change will likely involve both reductions in emissions and the capture of carbon dioxide from the atmosphere. Lithium nitride can be used to simply capture carbon dioxide and convert it into $\mathrm{Li}_{2} \mathrm{CN}_{2}$ as a fertilizer and $\mathrm{C}, \mathrm{N}_{2}$, and $\mathrm{O}_{2}$ by a simple process which will eventually reduce climate change and shall balance the ecosystem and biosphere tremendously.

\section{Funding}

This research is supported by Green Globe Technology under the grants RD02016-04. Any findings, conclusions, and recommendations expressed in this paper are solely those of the author and do not necessarily reflect those of the Green Globe Technology.

\section{Competing interests}

The author declares that he has no competing interests.

Received: 6 June 2016 Accepted: 25 August 2016

Published online: 09 September 2016

\section{References}

1. Alley RB, Marotzke J, Nordhaus WD, Overpeck JT, Peteet DM, Pielke RA Jr, Pierrehumbert RT, Rhines PB, Stocker TF, Talley LD, Wallace JM (2003) Abrupt climate change. Science 299(5615):2005-2010

2. Arnell NW, Nicholls R, Livermore MJL, Kovats SR, Levy P, Parry ML, Gaffin S (2004) Climate and socioeconomic scenarios for climate change impacts assessments: characterising the SRES storylines. Glob Environ Chang 14:3-20 
3. Barnett J, Adger WM (2003) Climate dangers and atoll countries. Clim Chang 61:321

4. Dessai S, Adger WN, Hulme M, Köhler J, Turnpenny JP, Warren R (2004) Defining and experiencing dangerous climate change. Clim Chang 64(1-2): $11-25$

5. Forest CE, Stone PH, Sokolov AP, Allen MR, Webster MD (2001) Quantifying uncertainties in climate system properties with the use of recent climate observations. Science 295:113-117

6. Hossain, F.M., 2016: "Solar energy integration into advanced building design for meeting energy demand and environment problem" Internal Journal of Energy Research DOI: 10.1002/er.3525.

7. Hossain FM (2016) In situ goethermal energy technology: an approach for building cleaner and green environment. J Ecol Eng 17:49-55

8. Hitz S, Smith J (2004) Estimating global impacts from climate change. Glob Environ Chang 14(3):201-218

9. Mann ME, Bradley RS, Hughes MK (1998) Global-scale temperature patterns and climate forcing over the past six centuries. Nature 392:779-787

10. Mastrandrea MD, Schneider SH (2004) Probabilistic integrated assessment of 'dangerous' climate change. Science 304:571-575

11. Naomi, H., 2010. Mathematical modeling of climate change examining the diurnal temperature range. Thesis at Math Department, Bryn Mawr College Victor Donny

12. O'Neill BC, Oppenheimer M (2002) Climate change-dangerous climate impacts and the Kyoto protocol. Science 296(5575):1971-1972

13. O'Neill BC, Oppenheimer M (2004) Climate change impacts sensitive to path to stabilization. Proc Natl Acad Sci 101:16,411-16,416

14. Parmesan C, Yohe G (2003) A globally coherent fingerprint of climate change impacts across natural systems. Nature 421:37-42

15. Rial JA, Pielke RA Sr, Beniston M, Claussen M, Canadell J, Cox P, Held H, De Noblet-Ducoudré N, Prinn R, Reynolds JF, Salas JD (2004) Nonlinearities, feedbacks and critical thresholds within the Earth's climate system. Clim Chang 65:11

16. Schneider SH (2004) Abrupt non-linear climate change, irreversibility and surprise. Glob Environ Chang 14:245-258

\section{Submit your manuscript to a SpringerOpen ${ }^{\circ}$ journal and benefit from:}

- Convenient online submission

- Rigorous peer review

- Immediate publication on acceptance

- Open access: articles freely available online

- High visibility within the field

- Retaining the copyright to your article 